\title{
ANALYSIS OF SPATIOTEMPORAL CHARACTERISTICS OF DROUGHT IN AN ARID REGION OF NORTHWEST CHINA
}

\author{
WeI, W. ${ }^{1}-$ PANG, S. F. ${ }^{*}-$ XIE, B. B. ${ }^{2}-$ ZHOU, J. J. ${ }^{1}-$ ZHOU, L. ${ }^{3}$ \\ ${ }^{1}$ College of Geography and Environmental Science, Northwest Normal University, 967 Anning \\ East Road, Lanzhou 730070, Gansu, China \\ (e-mails:weiweigis2006@126.com-W.Wei; $540628961 @ q q . c o m-J . J . Z h o u)$ \\ ${ }^{2}$ School of Urban Economics and Tourism Culture, Lanzhou City University, Lanzhou 730070, \\ Gansu, China \\ (e-mail:116543885@qq.com) \\ ${ }^{3}$ Faculty of Geomatics, Lanzhou Jiaotong University, Lanzhou 730070, Gansu, China \\ (e-mail: zhougeo@126.com) \\ *Corresponding author \\ e-mail:psfei1993@163.com; phone: +86-181-9419-9139 \\ (Received $4^{\text {th }}$ Feb 2020; accepted $22^{\text {nd }}$ May 2020)
}

\begin{abstract}
Drought, as a natural disaster, affects the local environment and agricultural production. Drought monitoring plays a crucial role in preventing and mitigating drought, especially Meteorological and Agricultural Drought (IMAD) monitoring. To better monitoring IMAD, a new comprehensive drought index, called Meteorological and Agricultural Drought Index (MADI), was developed in this study, which combined the Standardized Precipitation Evapotranspiration Index (SPEI) and the Temperature Vegetation Dryness Index (TVDI). And, the spatiotemporal characteristics of drought were analyzed by the methods of the frequency, comparison and regionalization in Gansu Province of China during 2000-2016. The results showed that: (1) The meteorological and agricultural drought always occurred, while there was a difference in time of appearance; the IMAD in Gansu Province was mainly light and moderate, becoming serious from southeast to northwest. (2) MADI was temporally wellmatched to the drought affected area, soil moisture and NPP. (3) The IMAD based on MADI can reflect both meteorological and agricultural drought well in time and space. (4) According to the drought frequency, the study area was divided into six regions, and most of the study area was the stable drought type. For different regions, government should take timely measures to prevent drought.
\end{abstract}

Keywords: SPEI, TVDI, MADI, integrated meteorological and agricultural drought (IMAD), arid region, China

\section{Introduction}

Drought caused by the unbalance supply of water, is one of the most frequent, widespread, disastrous and costly natural disasters in the world (Lloyd-Hughes and Saunders, 2002). It can significantly impact on socio-economy, agricultural production, water resources and ecosystem function (Lei et al., 2016). With climate warming, drought occurred frequently in China during the past decades (Liang et al., 2014; Yu et al., 2014; Zhang et al., 2018), especially in the northwestern region (Ren et al., 2014). Gansu Province is a typical arid area and sensitive to drought in the northwestern China, where the crop production and people's lives are largely affected by drought. Therefore, studying the drought characteristics in this area is conducive to comprehensively exploring the drought conditions in arid areas, and can provide more useful suggestions for drought in similar areas in the world. 
Drought is generally classed into the meteorological, agricultural, hydrological, socio-economic drought (Maity et al., 2016). The meteorological drought (MeD) and agricultural drought (AD) are closely related to national food security and social stability (Liu et al., 2015). MeD refers to the water deficiency caused by the unbalance between precipitation and evapotranspiration, and AD refers to soil moisture less than the water requirement of vegetation (Sheffield and Wood, 2012). Various indices of $\mathrm{MeD}$ and $\mathrm{AD}$ have been proposed by many scholars (Zargar et al., 2011; Hao and Singh, 2015).

MeD indices are widely applied to monitor drought (Zhang et al., 2011), such as the percentage of Precipitation anomaly (Pa) (Van Rooy, 1965), Standardized Precipitation Index (SPI) (McKee et al., 1993), Standardized Precipitation Evapotranspiration Index (SPEI) (Vicente-Serrano et al., 2010), Palmer Drought Severity Index (PDSI) (Palmer, 1965), and Compound Index (CI) (Zou et al., 2010). Among them, while SPI and Pa are simple to calculate, they only consider precipitation and cannot reflect drought change as the climate warming (Guo et al., 2018). PDSI can be calculated by temperature, precipitation, runoff and soil moisture, whereas it is complicated to calculate and cannot reflect multi-scale characteristics of droughts (Yao et al., 2017). CI is a comprehensive index, but it always exaggerates the actual drought situation. However, SPEI not only is a standardized and multi-scale drought monitoring index, but also considers precipitation and evapotranspiration which can reflect the drought condition accurately as the climate warming (Begueria et al., 2014). Thus, SPEI is the most suitable index to monitor meteorological drought.

Most of $\mathrm{AD}$ indices are remote sensing indices, which can objectively reflect the drought condition. And those indices can be classified into three categories: some indices detect AD by Land Surface Temperature (LST), such as Apparent Thermal Inertia (ATI) (Price, 1985); some indices use the vegetation change monitoring to detect drought, such as Anomaly Vegetation Index (AVI) (Chen et al., 1994) and Vegetation Condition Index (VCI) (Kogan, 1995); some indices based on the feature space of LST and vegetation indices, such as Vegetation Supply Water Index (VSWI) (Carlson et al., 1994) and Temperature Vegetation Dryness Index (TVDI) (Sandholt et al., 2002). Different indices above has different application conditions. For example, ATI is only suitable in bare or low vegetation coverage area (Wu et al., 2012); AVI and VCI always lag behind the drought monitoring (Sun et al., 2012); VSWI and TVDI have high requirements for the study area where the vegetation coverage should vary from bare to high vegetation (Yang et al., 2009). According to the vegetation coverage of the Gansu Province, TVDI was selected to monitor AD because of its simple computation and high precision (Bai et al., 2017).

Due to the independence and interaction of $\mathrm{MeD}$ and $\mathrm{AD}$, the integrated drought based on MeD and AD is crucial in the development of drought research. Many scholars have developed the comprehensive drought indices and minoring drought characteristics. For example, Hao and AghaKouchak (2013) developed Multivariate Standardized Drought Index (MSDI) based on SPI and Standardized Soil Moisture Index (SSM); Li et al. (2017) improved MSDI and developed Modified Multivariate Standardized Drought Index (MMSDI) based on SPEI and SSI, which makes up the deficiencies of MSDI. However, the physical significance, calculation methods and monitoring accuracy of these drought indices may need to be improved. Besides, it is lack of the comprehensive drought indices for the arid areas. Thus, there are some issues to be considered in the future research: (1) how to develop a comprehensive and 
accurate comprehensive based on a simple calculation? (2) how to minoring comprehensive drought characteristics by a new drought index?

Given the introduction above, this study aims to develop a new comprehensive drought index to investigate the drought characteristics in Gansu Province of the northwest China: (1) select the optimal indices of MeD and $\mathrm{AD}$ for the arid region, and analyze the $\mathrm{MeD}$ and $\mathrm{AD}$ characteristics; (2) develop Meteorological and Agricultural Drought Index (MADI) based on SPEI and TVDI, and analyze the spatiotemporal characteristics of Integrated Meteorological and Agricultural drought (IMAD); (3) validate the MADI from several aspects; (4) determine the drought partitions according to the drought frequency of IMAD, and provide targeted suggestions.

\section{Data and methods}

\section{Study area}

Gansu Province is located in the northwest region of China $\left(32^{\circ} 11^{\prime}-42^{\circ} 57^{\prime} \mathrm{N}, 92^{\circ} 13^{\prime}-\right.$ $108^{\circ} 46^{\prime} \mathrm{E}$ ), which covers various climatic types from humid to semi-humid, and from semi-arid to arid (Fig. 1). The annual average temperature ranges from 0 to $16{ }^{\circ} \mathrm{C}$ and the annual precipitation ranges from $30 \mathrm{~mm}$ to $860 \mathrm{~mm}$. Gansu Province lies among the Loess Plateau, the Tibetan Plateau and the Mongolian Plateau. The landscape is complex and diverse, including plateaus, mountains, valleys and deserts, and it is covered from bare areas to high vegetation. And there are six geomorphic units, including the Gannan Plateau, the Longnan Mountainous Region, the Loess Plateau in the middle and east of Gansu, the Qilian Mountain Region, the Hexi Corridor and the northern zone of the Hexi Corridor. Affected by climate, topography, geographic location and human activities, natural disasters in the study area occur frequently, and drought is the most serious disaster, which has a major impact on agriculture, economy and human health.

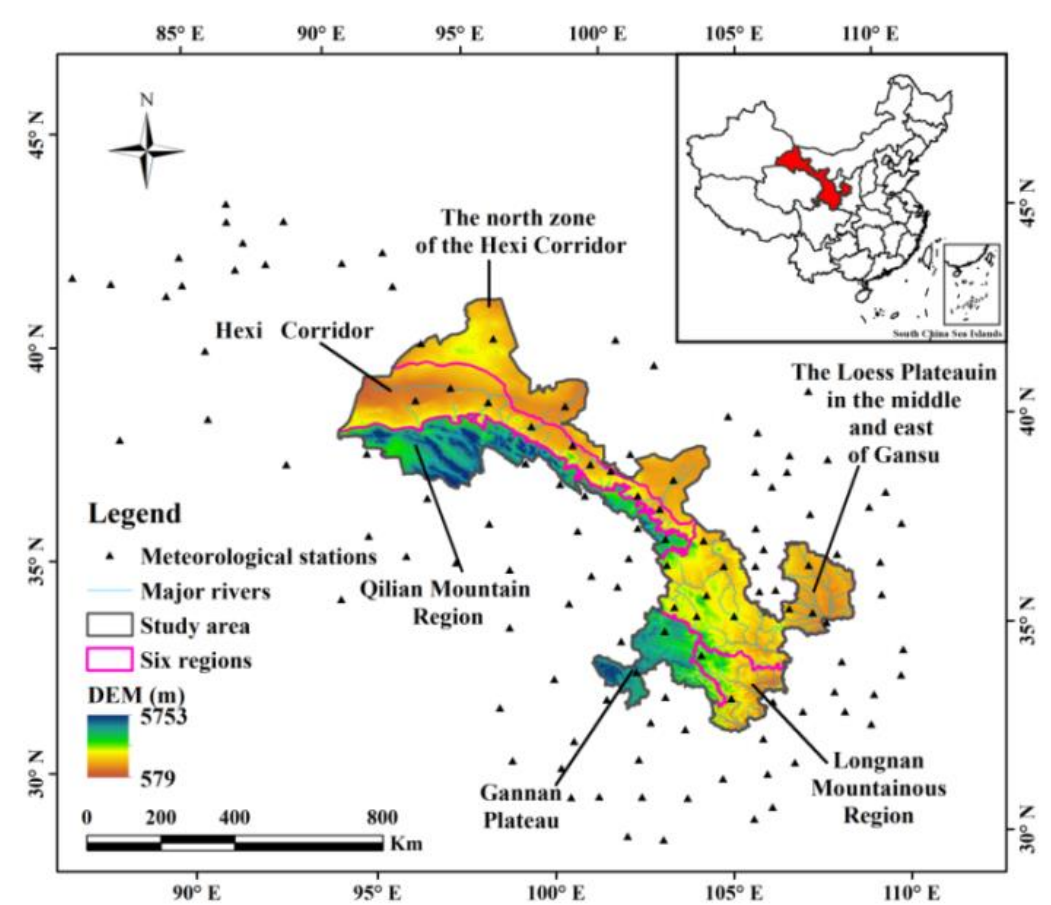

Figure 1. The location of the study area 


\section{Data and processing}

\section{Meteorological station data}

The meteorological data from 1960 to 2016 were obtained from the China Meteorological Data Sharing Service System (http://cdc.cma.gov.cn/), including monthly precipitation and temperature. In order to reduce error of spatial distribution, 35 stations were eliminated in the original datasets due to the observation data less than 30 years during 1961-2016 or missing observation data more than one year during 2000-2016. And 120 meteorological gauge stations were selected, including 26 stations in Gansu, 8 stations in the Inner Mongolia, 9 stations in Ningxia, 23 stations in Qinghai, 16 stations in Shanxi, 20 stations in Sichuan and 18 stations in Xinjiang. In this study, the meteorological drought index was calculated based on monthly precipitation and temperature data from 1960 to 2016. However, the meteorological data and remote sensing data were different in time range, and there were difference between the results of meteorological drought index and agricultural index. Therefore, the result of meteorological drought index during 2000-2016 was extracted to show and analyze drought in this study.

\section{Remote sensing data}

The Moderate Resolution Imaging Spector radiometer (MODIS) data were obtained from National Aeronautics and Space Administration (NASA), including four products of Normalized Difference Vegetation Index (NDVI) (MOD13A2), LST (MOD11A1), Net Primary Productivity (NPP) (MOD17A3) and surface reflectance (MOD09A1) (Table 1). Four tiles (h25v04, h25v05, h26v04, h26v05) were used to cover the study area. Table 1 provides the detailed information on the MODIS products.

Table 1. MODIS data information

\begin{tabular}{c|c|c|c|c}
\hline Production & Time & $\begin{array}{c}\text { Spatial } \\
\text { resolution }\end{array}$ & $\begin{array}{c}\text { Temporal } \\
\text { resolution }\end{array}$ & Source \\
\hline MOD13A3 NDVI & $2000-2016$ & $500 \mathrm{~m}$ & 16 - Day & NASA (http://modis.gsfc.nasa.gov ) \\
\hline MOD11A2 LST & $2000-2016$ & $1 \mathrm{~km}$ & 8 -Day & \\
\hline $\begin{array}{c}\text { MOD09A1 surface } \\
\text { reflectance (Band 6 } \\
\text { and Band 7) }\end{array}$ & $2000-2016$ & $1 \mathrm{~km}$ & 8-Day & $\begin{array}{c}\text { Numerical Terradynamic Simulation } \\
\text { Group (NTSG) at the University of } \\
\text { Montana } \\
\text { (http://www.ntsg.umt.edu/project/mod16) }\end{array}$ \\
\hline MOD17A3 NPP & $2000-2015$ & $1 \mathrm{~km}$ & Year & \\
\hline
\end{tabular}

\section{Global land data assimilation system (GLDAS) soil moisture data}

Global Land Data Assimilation System (GLDAS) data from NASA (https://disc.gsfc.nasa.gov/) is the global land surface assimilation data based on satellite data, land surface models and ground observation data jointly released by NASA and the National Oceanic and Atmospheric Association (NOAA). The GLDAS soil moisture data $\left(0.25^{\circ} \times 0.25^{\circ}\right.$, unit of $\left.\mathrm{kg} / \mathrm{m}^{2}\right)$ are global monthly data generated by the GLDASNoah model, including 4 layers of 0-10 cm, 10-40 cm, 40-100 cm, and 100-200 cm. These data have been widely used worldwide and show actual soil moisture (Zawadzki and Kedzior, 2015). In addition, soil moisture data in the soil layer of $0-10 \mathrm{~cm}$ can 
better reflect drought conditions (Pang et al., 2019), so the soil moisture in the $0-10 \mathrm{~cm}$ soil layer from 2000 to 2016 was selected to evaluate the proposed drought index.

\section{Other data}

Disaster data were obtained from the crop and disaster database of the Ministry of Agriculture and Rural Affairs of the People's Republic of China, including types, area and degree of disaster. In this study, crop area affected by drought in Gansu Province during 2000-2016 was expressed the actual drought condition and verified the results of this study.

\section{Drought indices}

\section{Standardized precipitation evapotranspiration index (SPEI)}

The SPEI can show the water deficit for a certain temporal scale at a location to the historical average of the cumulative moisture deficit (Li et al., 2012). In this study, SPEI is calculated using the SPEI package in the R software environment (Santiago Beguería and Vicente-Serrano, 2013). There are nine categories of SPEI according to the World Meteorological Organisation, National Standard of Meteorological and Agricultural Drought in China, and the actual situation in Gansu (WMO, 2012; Ramkar and Yadav, 2018) (Table 2). It reflects different drought characteristics based on SPEI in different time scales, and SPEI-3, SPEI-6, and SPEI-12 represent seasonal, half a year, and annual accumulated drought condition, respectively (Shi et al., 2017). Therefore, SPEI12 was selected to monitoring drought in this study.

Table 2. Classification of SPEI

\begin{tabular}{c|c|c|c}
\hline Category & SPEI value & Category & SPEI value \\
\hline Extreme Wet $(\mathrm{EW})$ & $(2.0,+\infty)$ & Light Drought (LD) & $(-1,-0.5]$ \\
Severe Wet (SW) & $(1.5,2]$ & Moderate Drought (MD) & $(-1.5,-1]$ \\
Moderate wet (MW) & $(1,1.5]$ & Severe Drought (SD) & $(-2,-1.5]$ \\
Light Wet (LW) & $(0.5,1]$ & Extreme Drought (ED) & $(-2,-\infty)$ \\
Normal (N) & $(-0.5,0.5]$ & & \\
\hline
\end{tabular}

\section{Temperature vegetation dryness index (TVDI)}

The obviously negative correlation between NDVI and LST is closely related to soil moisture (Yu and Chen, 2010). The scatter plot of NDVI and LST has a triangular shape when vegetation coverage and soil moisture vary widely (Price, 1990). In the NDVILST triangle feature space (Fig. 2), the point A and B indicate the dry and wet bare soil, respectively. The point $\mathrm{C}$ indicates the area where soil moisture is sufficient and the surface is completely covered by vegetation with strong transpiration. With the surface vegetation coverage increasing, LST decreases and evaporation increases at the same time. The edge AC, as the dry edge of the NDV-LST feature space, indicates low soil moisture and low surface evapotranspiration in the area. The edge BC, as the wet edge of the NDVI-LST feature space, indicates a sufficient soil moisture and equal evapotranspiration and potential evapotranspiration in the area.

Based on the relationship between NDVI and LST, the Temperature Vegetation Dryness Index (TVDI), can monitor the soil moisture (Sandholt et al., 2002). As TVDI 
increases, soil moisture decreases and the drought becomes more severe. According to the actual drought condition, the classifications of TVDI were shown in Table 3 (Liu et al., 2017).

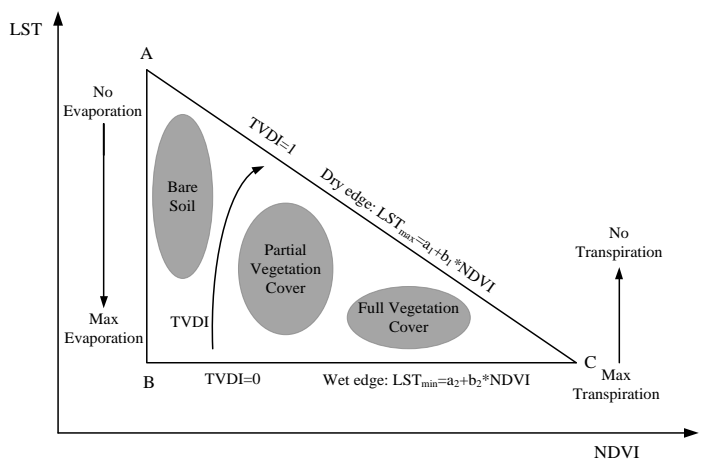

Figure 2. The NDVI-LST triangle space and definition of the TVDI

Table 3. Classification of TVDI

\begin{tabular}{c|c|c|c|c|c}
\hline Category & TVDI value & Category & TVDI value & Category & TVDI value \\
\hline EW & {$[0,0.1]$} & $\mathrm{LW}$ & $(0.3,0.4]$ & $\mathrm{MD}$ & $(0.7,0.8]$ \\
SW & $(0.1,0.2]$ & $\mathrm{N}$ & $(0.4,0.6]$ & $\mathrm{SD}$ & $(0.8,0.9]$ \\
MW & $(0.2,0.3]$ & $\mathrm{LD}$ & $(0.6,0.7]$ & $\mathrm{ED}$ & $(0.9,1]$ \\
\hline
\end{tabular}

\section{Meteorological and agricultural drought index (MADI)}

For better monitoring both MeD and AD at the same time, a new IMAD index, called Meteorological and Agricultural Drought Index (MADI), was proposed based on the Euclidean distance method. The Euclidean distance can measure the absolute distance between points in multi-dimensional space (Mesquita et al., 2017). Due to the objectivity, scientific nature and universality of Euclidean distance, it has been widely used in various geographically related fields, such as dry monitoring, ecological quality assessment, and vegetation monitoring (Amani et al., 2017; Shi et al., 2018; Li and Tian, 2013). The Euclidean distance can be expressed as (Eq. 1):

$$
\mathrm{D}(\mathrm{X}, \mathrm{Y})=\sqrt{\sum_{i=1}^{n}\left(x_{i}-y_{i}\right)^{2}}
$$

where $\mathrm{D}(\mathrm{X}, \mathrm{Y})$ is the Euclidean distance between the point $\mathrm{X}\left(\mathrm{x}_{1}, \mathrm{x}_{2}, \mathrm{x}_{3} \ldots, \mathrm{x}_{\mathrm{n}}\right)$ and the points $\mathrm{Y}\left(\mathrm{y}_{1}, \mathrm{y}_{2}, \mathrm{y}_{3} \ldots, \mathrm{y}_{\mathrm{n}}\right) ; \mathrm{n}$ is the multidimensional space.

Based on the above introduction, the MADI is developed as follows: first, a reference point is set (for research purposes, this point is the wettest point), and then, the Euclidean distance is calculated from each point to this reference point. When the calculated distance is longer, the drought value is higher; otherwise, the drought value is lower. The MADI value ranges from 0-200 and the higher MADI is drier. Its calculation is as follows $(E q .2)$ :

$$
\mathrm{MADI}=\frac{\sqrt{2}}{2} \sqrt{\left(N S P E I-N S P E I_{\max }\right)^{2}+\left(N T V D I-N T V D I_{\min }\right)^{2}}
$$




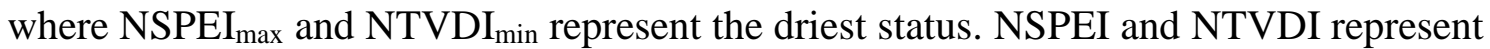
the normalized value of SPEI and TVDI in a point.

Due to the differences in ranges of drought classifications among different drought indices, a similar classification should be established to make these indices comparable (Esfahanian et al., 2017). Therefore, associated ranges were assigned and nine categories were identified, including four drought categories (light drought, moderate drought, severe drought, and extreme drought), four wet categories (light wet, moderate wet, severe wet, and extreme wet) and a normal category (normal). To obtain the drought score of each category of SPEI and TVDI, each drought index and category should be normalized using the linear scaling technique (Table 4).

Table 4. The normalized formula of each category using the linear scaling technique

\begin{tabular}{c|c|c|c}
\hline Category & Formula & Category & Formula \\
\hline $\mathrm{LW}$ & $I_{N}=\frac{I-a}{b-a}(0-25)$ & $\mathrm{LD}$ & $I_{N}=\frac{I-a}{b-a}(40-20)+20$ \\
\hline $\mathrm{MW}$ & $I_{N}=\frac{I-b}{c-b}(25-50)-25$ & $\mathrm{MD}$ & $I_{N}=\frac{I-b}{c-b}(60-40)+20$ \\
\hline $\mathrm{SW}$ & $I_{N}=\frac{I-c}{d-c}(50-75)-50$ & $\mathrm{SD}$ & $I_{N}=\frac{I-c}{d-c}(80-60)+20$ \\
\hline $\mathrm{EW}$ & $I_{N}=\frac{I-d}{e-d}(75-100)-75$ & $\mathrm{ED}$ & $I_{N}=\frac{I-d}{e-d}(100-80)+20$ \\
\hline $\mathrm{N}$ & $I_{N}=\frac{I-p}{q-p}(20-0)$ & & \\
\hline
\end{tabular}

I is the original drought/wet index value; IN is the normalized value of drought/wet index; $\mathrm{p}$ and $\mathrm{q}$ are the associated range of the normal category; $\mathrm{a}$ and $\mathrm{b}$ are the associated range of the light drought/wet category; $\mathrm{b}$ and $\mathrm{c}$ are the associated range of the moderate drought/wet category; $\mathrm{c}$ to $\mathrm{d}$ is the associated range of the severe drought/wet category; $d$ to $e$ is the associated range of the extreme drought/wet category

The classification of MADI was acquired from the classification of NSPEI and NTVDI. The calculation of MADI was shown as follows (Eq. 3):

$$
\begin{aligned}
\mathrm{MADI}_{m}= & \sqrt{\left(N S P E I_{m}-N S P E I_{\text {max }}\right)^{2}+\left(N T V D I_{m}-N T V D I_{\min }\right)^{2}} \\
& =\sqrt{\left(N S P E I_{m}+100\right)^{2}+\left(N T V D I_{m}+100\right)^{2}}
\end{aligned}
$$

where $\mathrm{MADI}_{\mathrm{m}}$ represent the boundary value of every category of MADI. NSPEI $\mathrm{m}$ and $\mathrm{NTVDI}_{\mathrm{m}}$ are the boundary value of every category of SPEI and TVDI.

The NSPEI, NTVDI and MADI classification were shown in Table 5.

Table 5. Classification of NSPEI, NTVDI and MADI

\begin{tabular}{c|c|c|c|c|c}
\hline Category & $\begin{array}{c}\text { NSPEI and } \\
\text { NTVDI value }\end{array}$ & MADI value & Category & $\begin{array}{c}\text { NSPEI and } \\
\text { NTVDI value }\end{array}$ & MADI value \\
\hline EW & {$[-100,-75]$} & {$[0,25]$} & LD & $(20,40]$ & $(120,140]$ \\
SW & $(-75,-50]$ & $(25,50]$ & MD & $(40,60]$ & $(140,160]$ \\
MW & $(-50,-25]$ & $(50,75]$ & SD & $(60,80]$ & $(160,180]$ \\
LW & $(-25,0]$ & $(75,100]$ & ED & $(80,100]$ & $(180,200]$ \\
N & $(0,20]$ & $(100,120]$ & & & \\
\hline
\end{tabular}




\section{Analysis methods}

\section{The frequency analysis of drought}

The drought frequency indicates the probability of drought occurrence and can be calculated as follows:

$$
F=\frac{n}{N} \times 100 \%
$$

where $\mathrm{n}$ is the number of drought occurrence in the time series. $\mathrm{N}$ is the total number of time points in the time series.

\section{Comparative analysis of the drought indices}

In the temporal scale, SPEI, TVDI and MADI are quantitatively compared using Probability of Detection (POD), False Alarm Ratio (FAR), Critical Success Index (CSI), and Effect of Detection (EOD) methods (Table 6) (Hao and AghaKouchak, 2014).

Table 6. The quantitative compared methods

\begin{tabular}{c|c|c|c|c}
\hline Method & POD & FAR & CSI & EOD \\
\hline \multirow{2}{*}{ Formula } & $\frac{H}{H+M}$ & $\frac{F}{H+F}$ & $\frac{H}{H+M+F}$ & $\frac{H+H N}{A}$ \\
\hline
\end{tabular}

$\mathrm{H}$ (Hit) denotes the grid number where SPEI or TVDI is drought and MADI is drought; $\mathrm{M}$ (Miss) denotes the grid number where SPEI or TVDI is drought and MADI is not drought; F (False Alarm) denotes the grid number where SPEI or TVDI is not drought and MADI is drought; HN (Hit Null) denotes the grid number where SPEI, TVDI, MADI are not drought; A (all) denotes the total number of grid

In the spatial scale, the consistent of meteorological drought, agricultural drought and IMAD based on SPEI, TVDI and MADI were analyzed using the coding method (Table 7). (a, b, c) is the code, among which a, b, c represents the drought condition of SPEI, TVDI and MADI, respectively. 1 and 2 indicate respectively drought and no drought.

Table 7. The code and type of consistency

\begin{tabular}{c|c|c}
\hline \multicolumn{2}{|c|}{ Type } & Code (a, b, c) \\
\hline \multirow{2}{*}{$\begin{array}{c}\text { The monitoring drought } \\
\text { result of SPEI, TVDI, MADI } \\
\text { are all consistent }\end{array}$} & SPEI, TVDI, MADI are all dry & $(1,1,1)$ \\
\cline { 2 - 3 } & None of SPEI, TVDI, MADI is dry & $(2,2,2)$ \\
\hline \multirow{3}{*}{$\begin{array}{c}\text { The monitoring drought } \\
\text { result of SPEI, TVDI, MADI } \\
\text { are not consistent }\end{array}$} & MADI and SPEI are dry, but TVDI is not dry & $(1,2,1)$ \\
\cline { 2 - 3 } & SPEI is dry, but TVDI and MADI are not dry & $(1,2,2)$ \\
\cline { 2 - 3 } & TVDI and MADI are dry, but SPEI is not dry & $(2,1,1)$ \\
\hline
\end{tabular}

\section{The method of drought type partition}

In order to better prevent and mitigate drought, drought type partition was obtained taking into consideration of the frequency of IMAD (Table 8). There are three types, 
including Stable Drought (StD), Stable Non-Drought (SND), and Fluctuation type of Drought and Non-Drought (F-D-ND). The StD includes Stable Light Drought (SLD), Stable Moderate Drought (SMD), Stable Severe Drought (SSD), Stable Extreme Drought (SED), and Fluctuation type of LD, MD, SD (F-LD-MD-SD).

Table 8. The partition type of drought

\begin{tabular}{|c|c|c|c|}
\hline & Type & \multicolumn{2}{|l|}{ Frequency } \\
\hline & Stable Non-Drought (SND) & \multicolumn{2}{|c|}{$0 \leq$ frequency of drought $\leq 20 \%$} \\
\hline \multicolumn{2}{|c|}{$\begin{array}{l}\text { Fluctuation type of Drought and Non-Drought (F- } \\
\text { D-ND) }\end{array}$} & \multicolumn{2}{|c|}{$20 \%<$ frequency of drought $\leq 70 \%$} \\
\hline \multirow{5}{*}{$\begin{array}{l}\text { Stable } \\
\text { Drought } \\
(\mathrm{StD})\end{array}$} & Stable Light Drought (SLD) & Frequency of LD > 70\% & \multirow{5}{*}{$\begin{array}{l}\text { Frequency of } \\
\text { drought }>70\end{array}$} \\
\hline & Stable Moderate Drought (SMD) & Frequency of $\mathrm{MD}>70 \%$ & \\
\hline & Stable Severe Drought (SSD) & Frequency of SD > 70\% & \\
\hline & Stable Extreme Drought (SED) & Frequency of ED > 70\% & \\
\hline & $\begin{array}{l}\text { Fluctuation type of Light Drought, } \\
\text { Moderate Drought, Severe Drought (F- } \\
\text { LD-MD-SD) }\end{array}$ & $\begin{array}{c}\text { Frequency of } \mathrm{LD} \leq 70 \%, \text { frequency } \\
\text { of } \mathrm{MD} \leq 70 \%, \text { frequency of } \\
\mathrm{SD} \leq 70 \%, \text { and frequency of } \\
\mathrm{ED} \leq 70 \%\end{array}$ & \\
\hline
\end{tabular}

\section{Results}

\section{The characteristics of meteorological and agricultural drought}

The characteristics of MeD based on SPEI-12

SPEI-12 value fluctuated around -0.5 and drought duration was long in each drought period (Fig. 3), indicated that the MeD always occurs in the study area. The northwest and southeast region was mainly affected by LD and N, respectively (Fig. 4a). LD occurred every year with occupying the largest area; the MD occurred in 12 years, and its largest occupied area occurred in 2000 and 2009; the SD occurred in 2006 and 2009; the ED only occurred in 2009 (Fig. 4b). Moreover, the largest drought area and the most drought categories were occurred in 2009, which indicated the most serious drought occur in 2009.

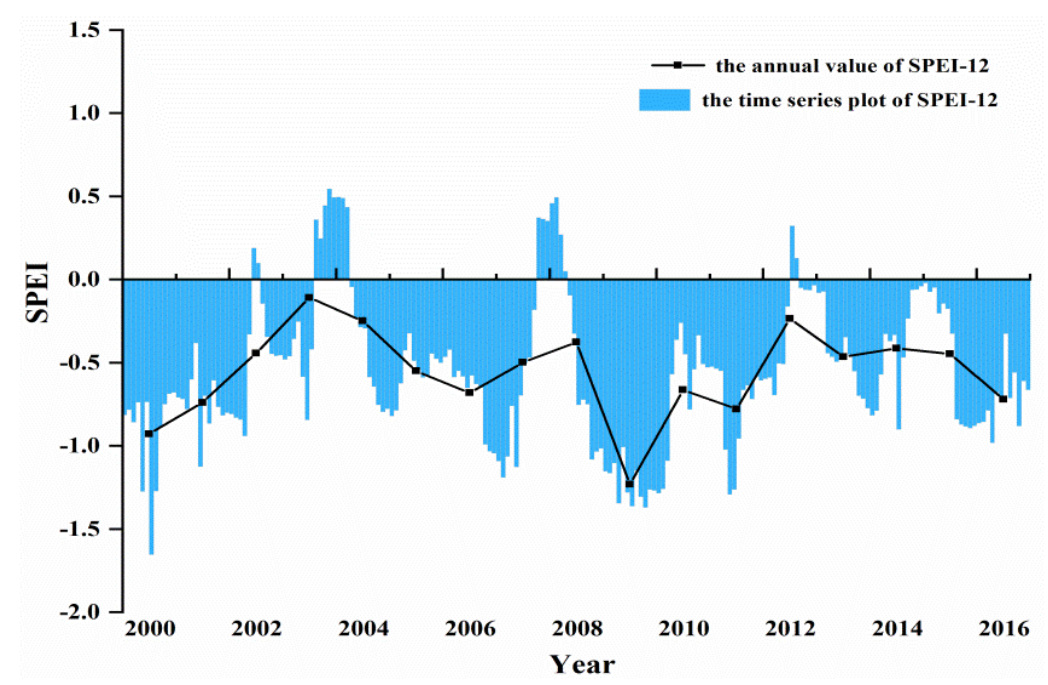

Figure 3. Time series plot of SPEI-12 

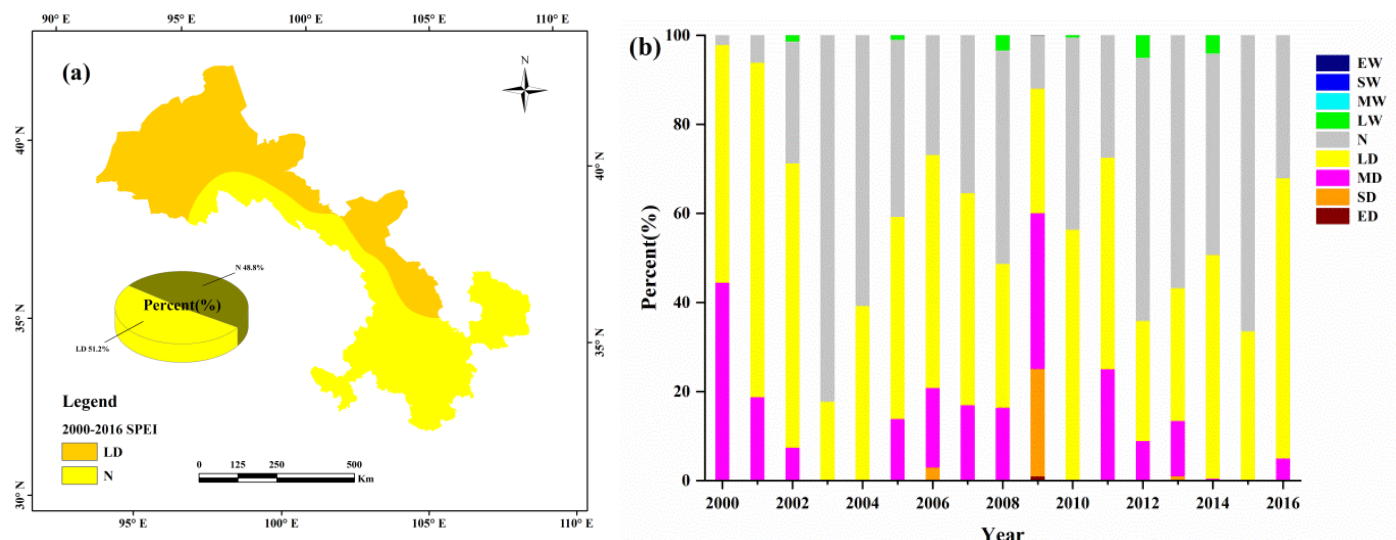

Figure 4. The spatiotemporal distribution of MeD based on the annual SPEI-12 values during 2000-2016: (a) the spatial distribution of the annual average values of SPEI-12 (b) and the yearly change of area percent of different $\mathrm{MeD}$ categories in years

The drought frequency value showed an increasing trend from southeast to northwest (Fig. 5). And the high drought frequency, approaching 60\%, mainly occurred in the northwestern region of the study area, especially the northern zone of the Hexi Corridor. The low drought frequency, less than $48 \%$, was mainly in the southeastern region, especially in the Longnan Mountainous Region and the Gannan Plateau. The frequency of LD and MD was higher than other drought categories; the frequency of ED was the least throughout the Province; the higher frequency value of light, moderate, severe, extreme drought all appeared in the northwestern Gansu and the northern zone of the Hexi Corridor. In a word, MeD was spatial and temporal in character.

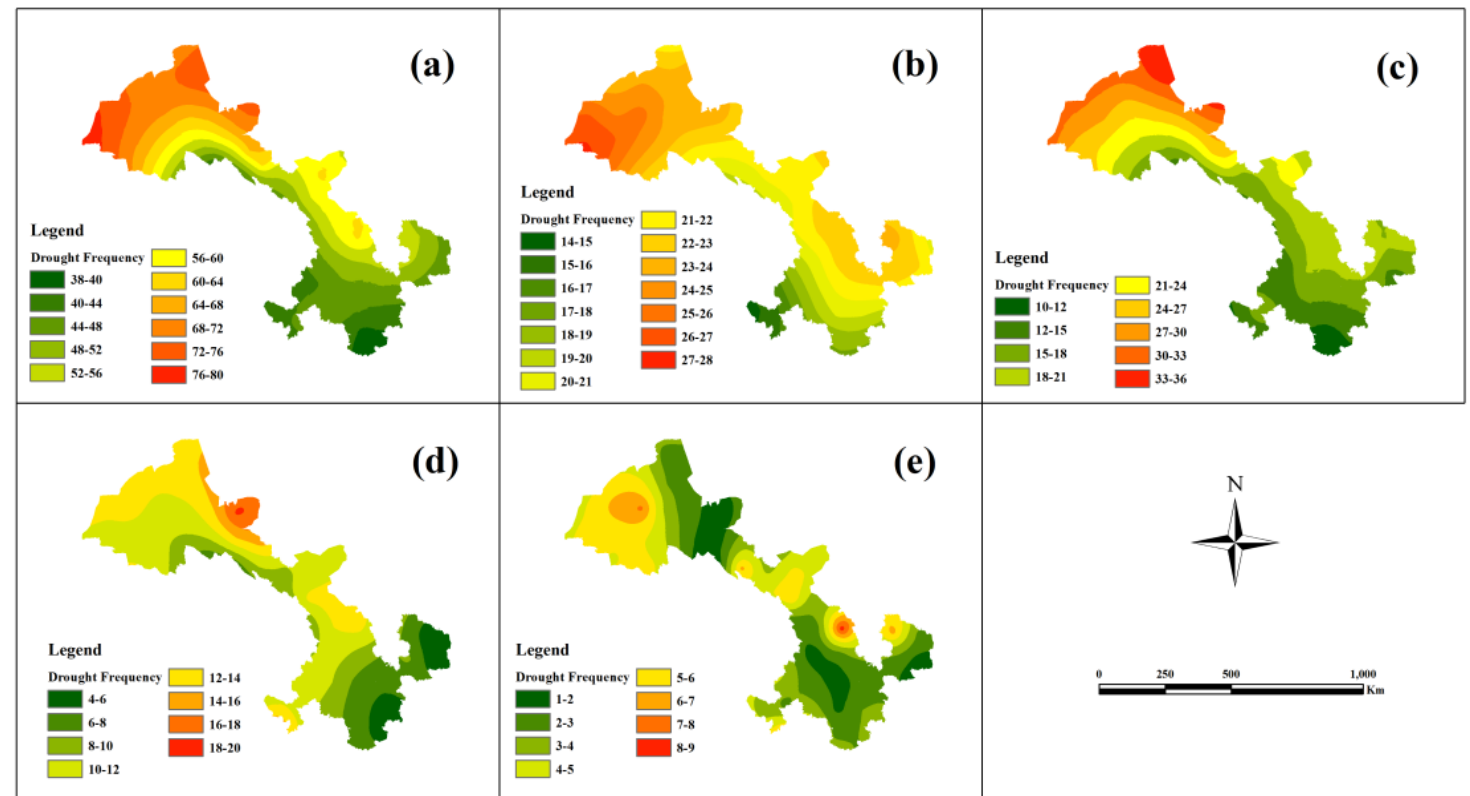

Figure 5. The spatial distribution of MeD occurrence frequency from 2000 to 2016: the frequency distribution of (a) drought occurrence, (b) LD occurrence, (c) MD occurrence, (d) SD occurrence, (e) ED occurrence 


\section{The characteristics of agricultural drought based on TVDI}

During 2000 to 2016, the mean TVDI value had a slight fluctuation around -0.69 (Fig. 6). And this study area was mainly affected by light and moderate drought. The lightest and most serious drought occurred in 2012 and 2002, respectively. Overall, AD always occurred in the past years and small changed in intensity.

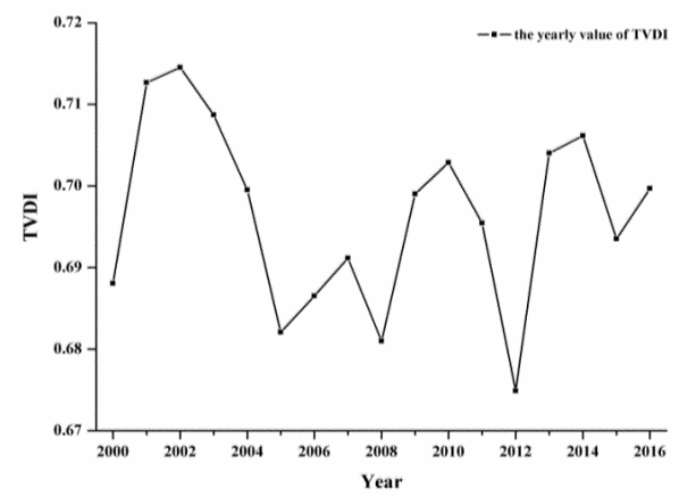

Figure 6. Time series plot of TVDI

Seed from annual average value of TVDI in 17 years (Fig. 7a), most of the study area was affected by light, moderate and severe drought, which was up to $85 \%$ in percentage; the MD percentage amounted to $40 \%$, and distributed widely; the ED percentage was approximately 5\% and concentrated in the desert; the percent of wet category approaches 7\%, mainly in the mountain regions. And the percent of drought was about $80 \%$ in the most years, among which the percent of MD was the most, followed by SD and LD, and ED was the least (Fig. 7b).
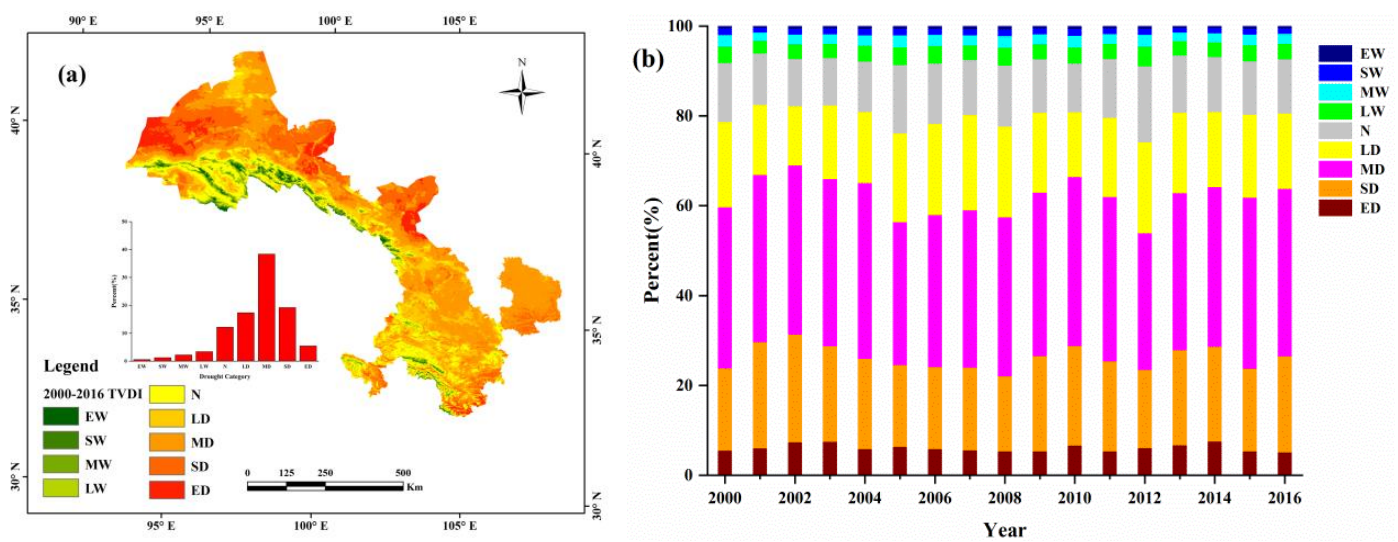

Figure 7. The spatio-temporal distribution of AD based on the annual TVDI values during 2000-2016: (a) the spatial distribution of the annual average values of TVDI (b) and the yearly change of area percent of different $A D$ categories in years

The drought frequency was from 0 to 100 and it increased from southeast to northwest (Fig. 8): the highest drought frequency, up to $90 \%$, was mainly in the northwestern region, especially the northern zone of the Hexi Corridor; the least drought frequency, less than 20\%, mainly occurred in Qilian Mountain Region. However, the 
frequency of different $\mathrm{AD}$ categories differed significantly. The frequency of LD and MD occurrence was relatively higher than other drought categories: the high frequency of LD was mainly distributed in the Loess Plateau of the middle and east of Gansu, the Hexi Corridor, surrounding areas of Qilian Mountain Region and the northern zone of the Hexi Corridor; the high frequency of MD mainly represented in Hexi Corridor and the northern zone of the Hexi Corridor; the high frequency of SD was mainly concentrated in the desert area; the frequency of ED was less than $10 \%$ in the whole province. Overall, AD had obvious spatiotemporal characteristics and small changed.

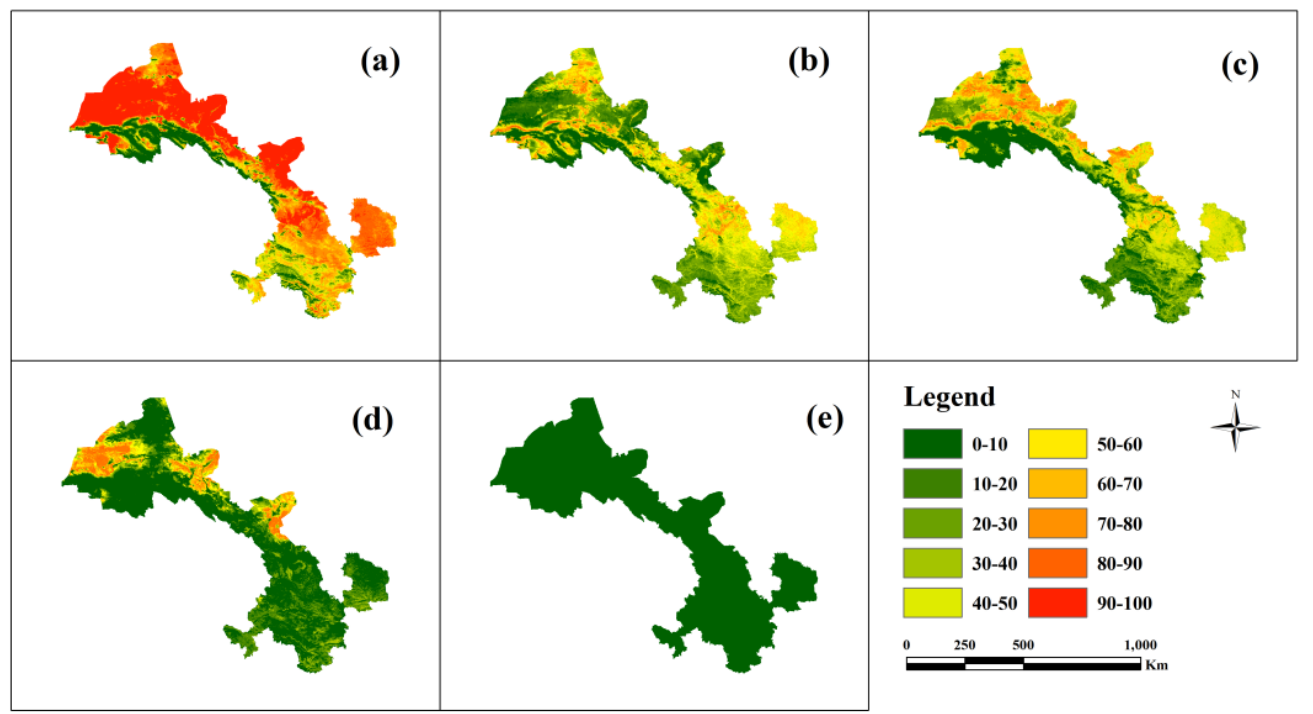

Figure 8. The spatial distribution of AD occurrence frequency from 2000 to 2016: the frequency distribution of (a) drought occurrence, (b) LD occurrence, (c) MD occurrence, (d) SD occurrence, (e) ED occurrence

\section{The characteristics of IMAD based on MADI}

From the time series plot of MADI during 2000-2016, slight fluctuation was from 130 to 145 in mean MADI value (Fig. 9). And this study area was mainly affected by LD in 17 years and only MD in 2009. Moreover, the lightest and most serious drought occurred in 2012 and 2009, respectively. From distribution of MADI (Fig. 10), most of the study area occurred IMAD and the sum area of LD and MD account for about $80 \%$. And area percentages of LD and MD accounted for the majority in17 years; the largest area and range of SD occurred in 2009, and ED also mainly occurred in 2009.

From the occurrence frequency of IMAD at 1-year interval in 17 years (Fig. 11), the drought frequency ranged from 0 to 100 , gradually increasing from southeast to northwest. The high drought frequency, over $90 \%$, was in the large part of the study region. The least drought frequency, less than $10 \%$, was concentrated in the Qilian Mountain Region. Moreover, the frequency differences of different drought categories were relatively high: the occurrence frequency of LD and MD were higher than other drought categories, being in the largest region of the whole province and in the northern zone of the Hexi Corridor, respectively; the high frequency of SD occurred in the desert area of the northern zone of the Hexi Corridor; the frequency of ED was nearly 2\% around the Province. Overall, IMAD had obvious spatiotemporal characteristics in Gansu Province. 


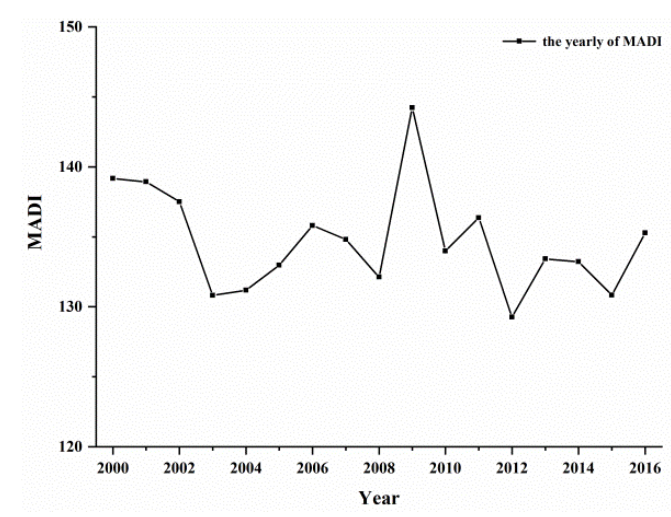

Figure 9. Time series plot of MADI
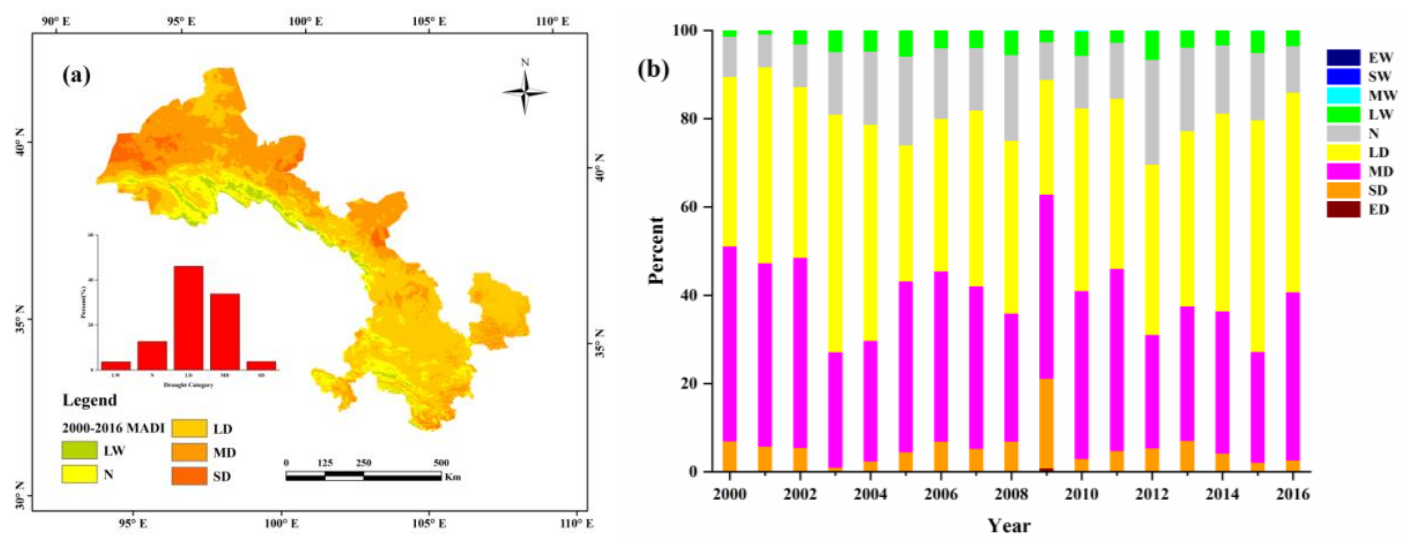

Figure 10. The spatiotemporal distribution of IMAD based on the annual values of MADI during 2000-2016: (a) the spatial distribution of the annual average values of MADI $(b)$ and the yearly change of area percent of different IMAD categories in years

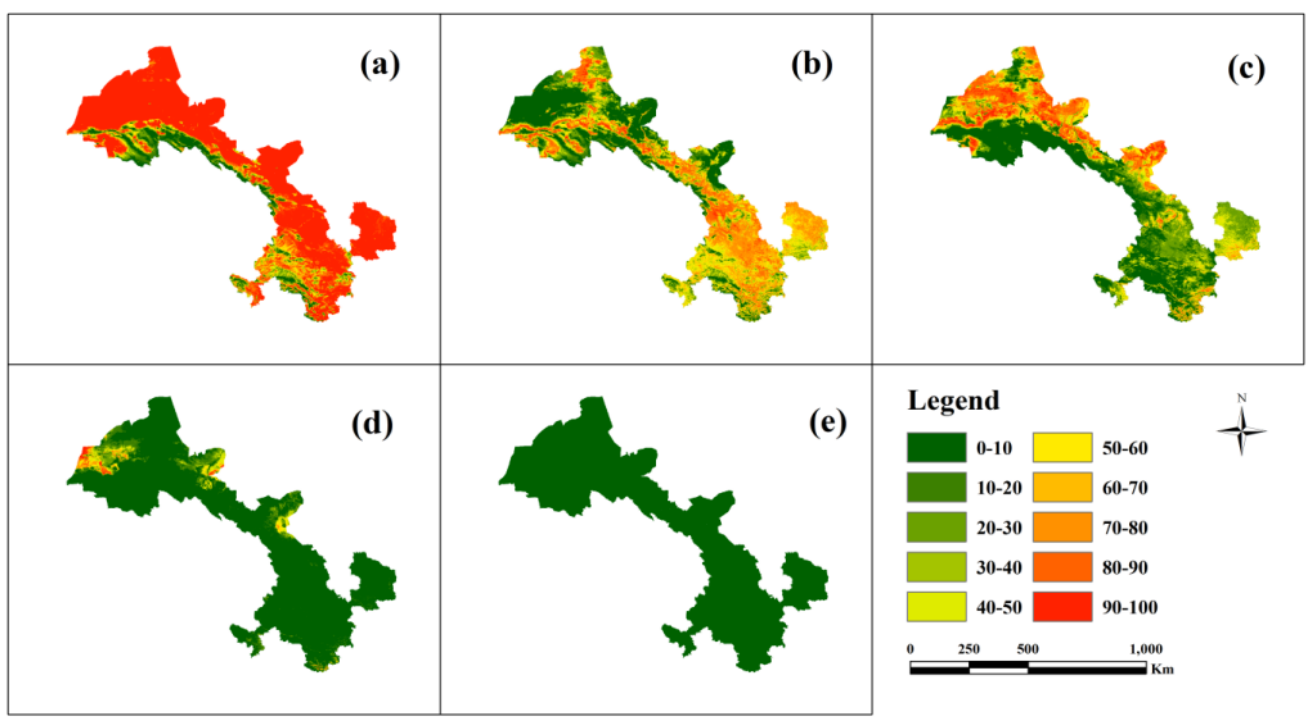

Figure 11. The spatial distribution of IMAD occurrence frequency from 2000 to 2016: the frequency distribution of (a) drought occurrence, (b) LD occurrence, (c) MD occurrence, (d) SD occurrence, (e) and ED occurrence 


\section{Discussion}

\section{The validation of the MADI}

\section{Drought affected area}

The drought affected area can directly reflect the drought impact extent and is often used for the accuracy validation of drought index (Du et al., 2013). The MADI was in good agreement with the variation of drought affected area (Fig. 12). The MADI showed a good positive linear correlation with the drought affected area, with the correlation coefficient $\mathrm{R}$ value reaching 0.7263 and passing 0.01 significance test. Meanwhile, the fluctuation changes, peaks and troughs of MADI were generally consistent with drought affected area in the 17 years. For example, MADI detected the worst drought in 2000 and 2009, and the drought affected areas in 2000 and 2009 were also relatively high; MADI detected the lightest drought in 2012, and the lowest drought affected areas also occurred in 2012. Thus, according to the above, MADI has a good accuracy in monitoring drought affected area.
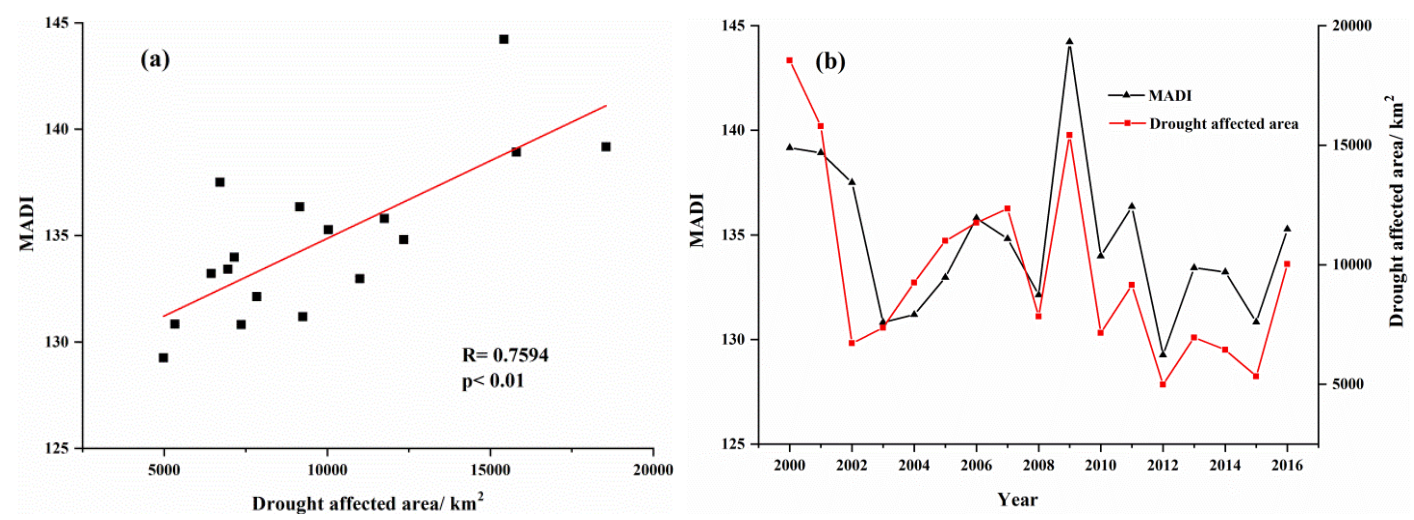

Figure 12. The relationship between MADI and drought affected area from 2000 to 2016

\section{GLDAS soil moisture and NPP}

Soil moisture, playing an important role in the formation and development of drought, is a direct indicator of the dry-wet condition in the land surface and is often verified the drought index (Cong et al., 2017; Hauser et al., 2016). Therefore, GLDAS soil moisture from 2000 to 2016 was selected for the accuracy of MADI. Due to the GLDAS soil moisture with $0.25^{\circ} \times 0.25^{\circ}$ spatial resolution, Inverse Distance Weighted (IDW) interpolation was performed to improve the spatial resolution to $1 \mathrm{~km} \times 1 \mathrm{~km}$. And the correlation between soil moisture and MADI was conducted based on pixels from 2000 to 2016 (Fig. 13a). The results showed that there was a negative correlation between soil moisture and MADI, accounted for about $85.34 \%$ of the study area. It proved that the drought change detected by MADI well matched the soil moisture change. Thus, MADI can better reflect the soil moisture change in the most areas.

Vegetation is an important feedback to the drought. When vegetation is subjected to drought stress, it will exhibit adaptive traits such as decreased photosynthesis and respiratory metabolism, thus reducing productivity (Drake et al., 2017). Therefore, the NPP can be as an effective tool to verify the MADI and directly reflect the drought distribution (Fig. 13b). It should be noted that the correlation between NPP and MADI was only distributed in the vegetation zone. Result showed the $\mathrm{R}$ value between the 
NPP and the MADI was negatively correlated in $88 \%$ of the regions with vegetation, indicating that the changes between the MADI and the NPP in most regions are consistent. Thus, the MADI can reflect the vegetation production status and better detect drought.

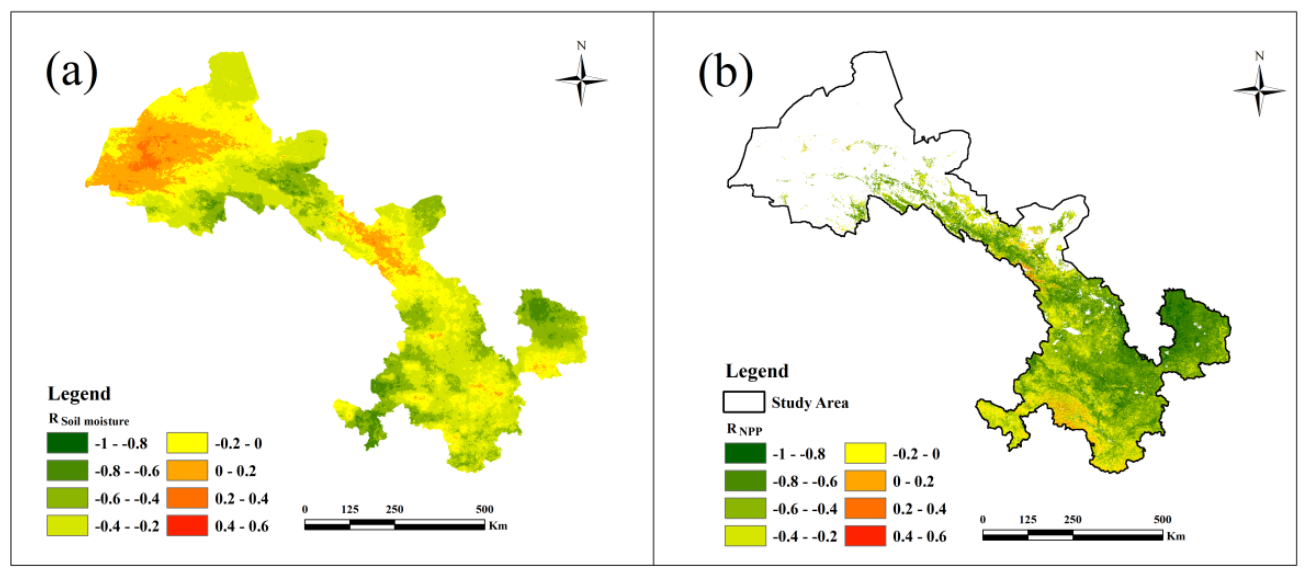

Figure 13. The spatial distribution of correlation coefficient $R$ : (a) soil moisture and MADI (b) and NPP and MADI

The difference of the MADI among MeD, AD and IMAD based on SPEI, TVDI and $M A D I$

POD, EOD, CSI and FAR can be used to evaluate the accuracy of IMAD in detecting of MADI from temporal aspect (Fig. 14). Result showed that POD, CSI and EOD had similar change characteristics and their values were closed to 0.9 from 2000 to 2016. The POD indicated that IMAD occurred in the same time and place when MeD/AD occurred; the EOD indicated that there was high the success rate to detect occurrence and no occurrence of IMAD and Med/AD. Moreover, the values of FAR were nearly 0 but not equal to 0, proving that IMAD was not only the simple addition of Med and AD, but also monitor the dry areas that cannot be monitored in Med and AD monitoring. Therefore, IMAD not only reflect $\mathrm{MeD}$ and $\mathrm{AD}$, but also is more comprehensive to reflect drought than $\mathrm{MeD}$ and $\mathrm{AD}$.

Comparing MeD, AD and IMAD spatially (Fig. 15), the area where MeD, AD and IMAD occurred and did not occur together, accounted for $59.3 \%$ of the study area: the type of $(1,1,1)$ that $\mathrm{MeD}, \mathrm{AD}$ and IMAD occurred together, was mainly distributed in Hexi Corridor, the northern zone of the Hexi Corridor and the northern region of the Loess Plateau in China; the type of $(2,2,2)$ that MeD, AD and IMAD all did not occur, was mainly distributed in the most parts of Qilian Mountain Region, parts of the Gannan Plateau and the Longnan Mountainous Region. Moreover, the different area of MeD, AD and IMAD accounts for 40.7\%, including four types $(2,1,1),(1,2,2),(1,2,1)$ and $(2,1,2)$ : the type of $(2,1,1)$, which AD and IMAD occurred but MeD did not occur, was distributed in the middle of Hexi Corridor, the most regions of the Loess Plateau, some parts of the Gannan Plateau and the Longnan Mountainous Region; the type of $(1,2,2)$ which $\mathrm{AD}$ and IMAD did not occurred but MeD occurred, was mainly in the western mountain area of Qilian Mountain Region.

In a word, the MADI is a good index and IMAD monitored by MADI can well reflect both Med and $\mathrm{AD}$ whether from temporal or spatial perspectives. 


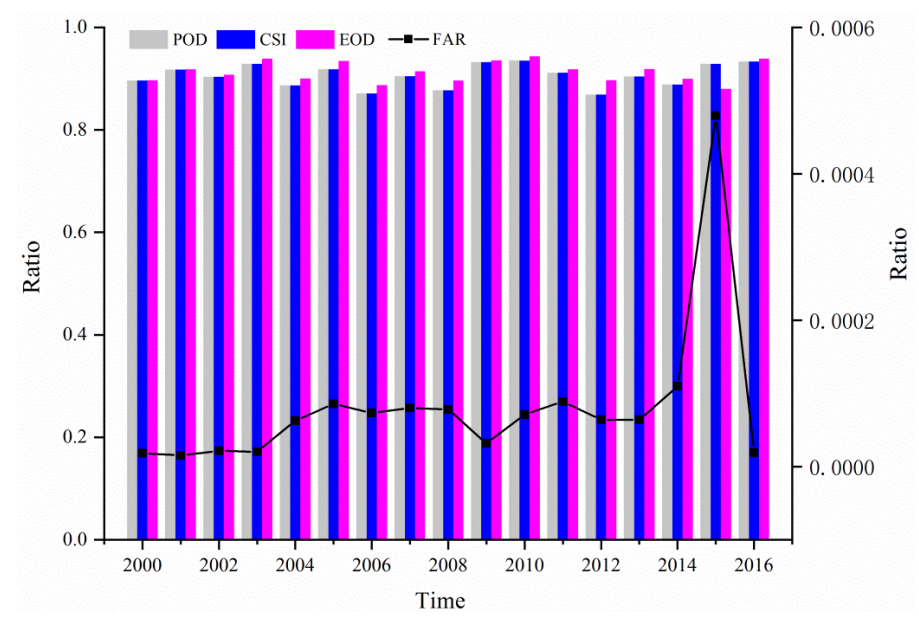

Figure 14. The temporal comparation among $M e D, A D$ and IMAD with the trend of $P O D, C S I$ and EOD from 2000 to 2016

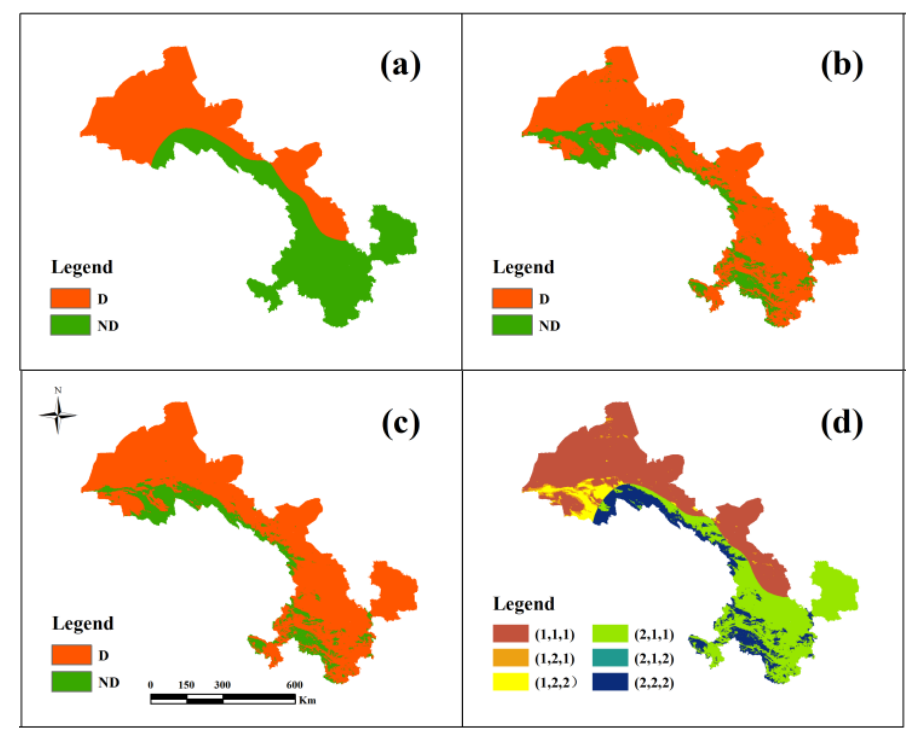

Figure 15. The spatially comparation among $M e D, A D$ and the IMAD: the spatial distribution of (a) MeD based on SPEI, (b) AD based on TVDI, (c) IMAD based on MADI, (d) and comparative result. $D$ and $N D$ referred to occurrence of drought and no drought

\section{Application in different drought partitions}

In accordance with the drought frequency, the study area was divided in to 6 partitions (Fig. 16), including SND, F-D-ND, F-LD-MD-SD, SLD, SMD, and SSD (Table 8). The area percentage of each was in the order: F-LD-MD-SD (29.8\%) > SLD $(25.5 \%)>\operatorname{SMD}(21.3 \%)>$ F-D-ND $(12.2 \%)>$ SND $(9.7 \%)>$ SSD $(1.5 \%)$. In different partitions, different measures for drought prevention and mitigation should be recommended.

(1) The region of SND is mainly distributed in high-vegetation mountains and grasslands. Because of low temperature and good water conservation, this region is rich in water resources. Moreover, the main agricultural type is animal husbandry with low water requirement. Therefore, the drought does not occur in this region (Xu, 2004). To 
maintain the current non-drought condition, the government should reduce the size and quantity of grazing, avoid excessive deforestation, and strengthen the protection and construction of grassland-forest. Meanwhile, the drought monitoring system and mountain reservoir should be established to monitoring drought conditions.

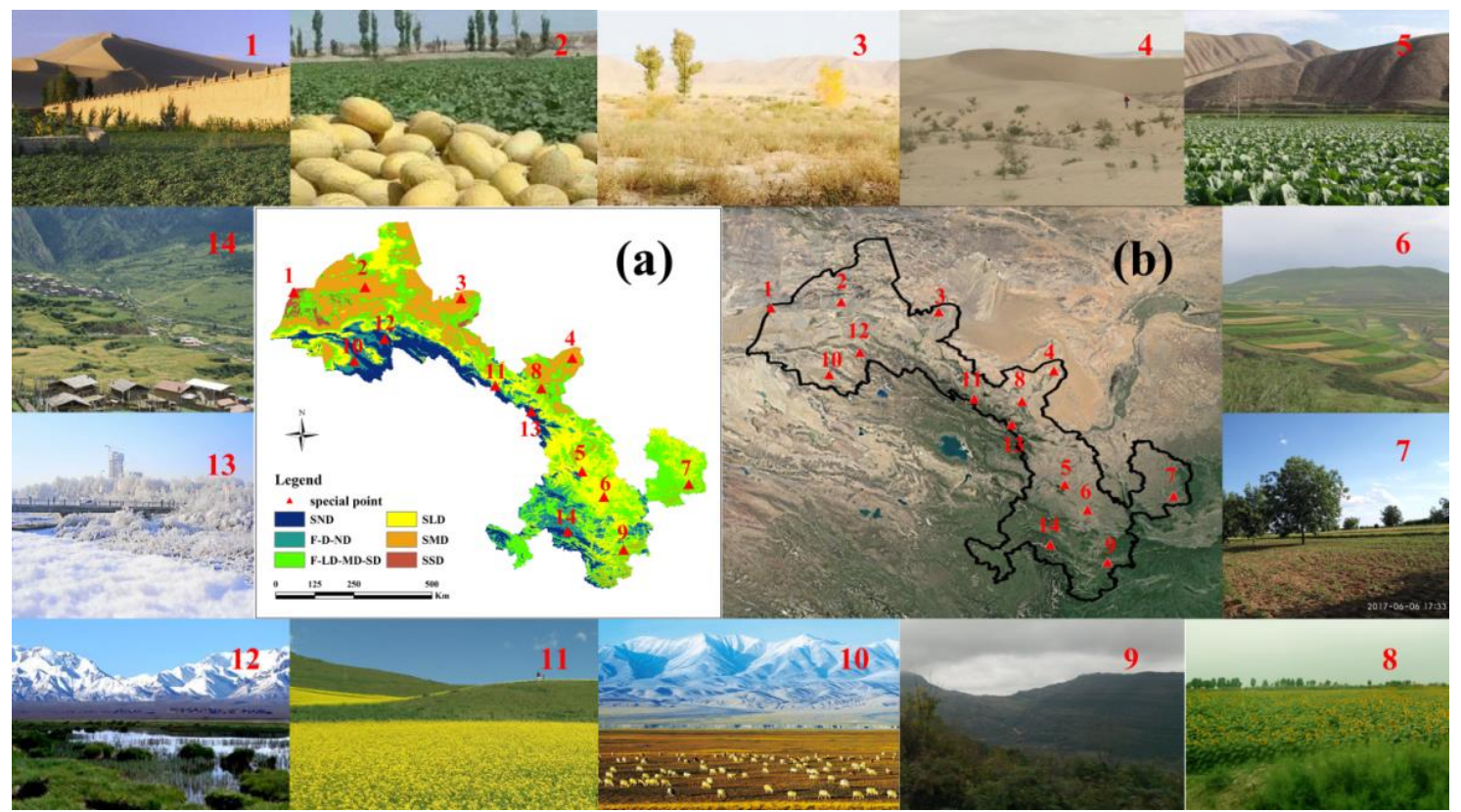

Figure 16. The partitions of IMAD in the study area: (a) the regionalization based on the drought frequency of MADI (b) and the Google map of the study area. The sample of 1-14 is the typical point in different regions: the picture of 1 represents SSD; the picture of 2, 3, 4 represent $S M D$; the picture of 5, 6, 7 represent $S L D$; the picture of 8, 9 represent $F-L D-M D$ $S D$; the picture of 10, 11 represent $F-D-N D$; and the picture of 12, 13, 14 represent $S N D$

(2) The region of F-D-ND is mainly distributed around the high mountains. The land use and agriculture type in this region was the same as SND. Hence, government should makes the similar measures with the region of SND to prevent and mitigate drought.

(3) The region of SLD is the main rained agriculture region with the scarce resources of surface water. Its main agricultural type is crop farming, with the main crops being wheat, maize and potato (Tian and Chen, 2011). In this region, government should promote the technology of "terracing + plastic film + rain collection + structural adjustment" and select various irrigation types, such as well canal joint irrigation, drip irrigation and infiltration. In addition, the government should invest in the construction of water conservancy facilities, reservoirs and rainwater collection facilities to increase the utilization of rainwater resources. Finally, famers should avoid wasting water resources and select the most suitable crops in dry area.

(4) The region of SMD is mainly distributed in desert, because of low precipitation vegetation coverage, high land surface temperature, and water shortage (Peng, 2011). From the perspective of desertification management, drought-tolerant plants, such as Tamarisk, Calligonum and white thorn, should be widely planted to enhance the ability of drought resistance and sand fixation; from the perspective of crop farming, the local government should take measures to encourage farmers to plant more drought-tolerant crops, such as cotton, cantaloupe, sunflower, red date, grape (Shi, 2013); and in terms of 
irrigation, the government should advocate water-saving irrigation, vigorously develop drip irrigation under mulch to reduce evaporation and leakage, and increase the utilization efficiency of water (Hou et al., 2009).

(5) The region of SSD is distributed in the desert area of the northwestern desert. The main crops are cotton and cantaloupe in this region. In order to deal with serious drought, the planting structure should be changed to reduce the proportion of food crops. And high-efficiency water-saving agriculture, featuring red globe grasps and special vegetables planting, should be promoted. In addition, farmers should raise their awareness of water conservation and build water storage facilities (Shu, 2012).

(6) The region of F-LD-MD-SD. In this region, the measures of prevent and mitigate drought should be similar with SLD, SMD and SSD.

\section{Research prospects}

This study started from two aspects of meteorology and agriculture, and combined a common meteorological drought index SPEI and agricultural drought index TVDI to develop a new comprehensive index MADI. And it proved that the MADI has advantages in drought monitoring: (1) It has good accuracy, which can well reflect the drought affected area, soil moisture and NPP situation; (2) It can well monitor the meteorological and agricultural drought at the same time, and can be applied to IMAD monitoring. However, the index uses meteorological station data from station observations and remote sensing data from satellite observations in the calculation, which may cause some errors in the results. Therefore, in future research, the data in index calculation should be improved and remote sensing data should be used as much as possible.

\section{Conclusions}

In this study, the MADI was developed based on SPEI and TVDI, validated and applied in Gansu Province of China. Results showed that the MeD and AD always occurred, but the most serious and lightest droughts occur at different times; according to the classification of MADI value, the study area was mainly affected by light and moderate IMAD, being gradually serious from southeast to northwest; the serious drought occurred in the northern zone of the Hexi Corridor and the non-drought occurred in the Qilian Mountain Region. Seen from the validation result of the MADI, MADI was well-matched to the drought affected area, soil moisture and NPP; MADI is a better monitor index than SPEI and TVDI, and can well monitor IMAD in the study area. Seen from the different drought partitions, the study area was divided into six regions according to the drought frequency, including SND, F-D-ND, F-LD-MD-SD, SLD, SMD, and SSD. Some suggestions were proposed for different drought partitions: in the regions of SND and F-D-ND, the drought monitoring system and mountain reservoir should be established; in the regions of F-LD-MD-SD, SLD, SMD, and SSD, government should adopt positive measures in drought-tolerant crops, agricultural construction, irrigation types and water conservancy projects. In summary, MADI is a good IMAD monitoring index, which can be used for future drought monitoring; a comprehensive single index method can be used to construct a drought index; different regions should make different drought prevention measures according to different drought characteristics. 


\section{REFERENCES}

[1] Amani, M., Salehi, B., Mahdavi, S., Masjedi, A., Dehnavi, S. (2017): TemperatureVegetation-Soil Moisture Dryness Index (TVMDI). - Remote Sensing of Environment 197: 1-14.

[2] Bai, J. J., Yuan, Y. U., Di, L. (2017): Comparison between TVDI and CWSI for drought monitoring in the Guanzhong Plain, China. - Journal of Integrative Agriculture 16: 389397.

[3] Begueria, S., Vicente-Serrano, S. M., Reig, F., Latorre, B. (2014): Standardized Precipitation Evapotranspiration Index (SPEI) revisited: parameter fitting, evapotranspiration models, tools, datasets and drought monitoring. - International Journal of Climatology 34: 3001-3023.

[4] Carlson, T. N., Gillies, R. R., Perry, E. M. (1994): A method to make use of thermal infrared temperature and NDVI measurements to infer surface soil water content and fractional vegetation cover. - Remote Sensing Reviews 9: 161-173.

[5] Chen, W. Y., Xiao, Q. G., Shen, Y. W. (1994): Application of the anomaly vegetation index to monitoring heavy drought in 1992. - Remote Sensing of Environment 9: 106112 .

[6] Cong, D. M., Zhao, S. H., Chen, C., Duan, Z. (2017): Characterization of droughts during 2001-2014 based on remote sensing: a case study of Northeast China. - Ecological Informatics 39: 56-67.

[7] Drake, J. E., Power, S. A., Duursma, R. A., Medlyn, B. E., Aspinwall, M. J., Choat, B., Creek. D., Eamus, D., Maier, C., Pfautsch, S., Smith, R. A., Tjoelker, M. G., Tissue, D. T. (2017): Stomatal and non-stomatal limitations of photosynthesis for four tree species under drought: a comparison of model formulations. - Agricultural and Forest Meteorology 247: 454-466.

[8] Du, L. T., Tian, Q. J., Yu, T., Meng, Q. Y., Jancso, T., Udvardy, P., Huang, Y. (2013): A comprehensive drought monitoring method integrating MODIS and TRMM data. International Journal of Applied Earth Observation and Geoinformation 23: 245-253.

[9] Esfahanian, E., Nejadhashemi, A. P., Abouali, M., Adhikari, U., Zhang, Z., Daneshvar, F., Herman, M. R. (2017): Development and evaluation of a comprehensive drought index. - Journal of Environmental Management 185: 31-43.

[10] Guo, H., Bao, A. M., Liu, T., Jiapaer, G. L., Ndayisaba, F., Jiang, L. L., Kurban, A., Maeyer, P. D. (2018): Spatial and temporal characteristics of droughts in Central Asia during 1966-2015. - Science of the Total Environment 624: 1523-1538.

[11] Hao, Z., AghaKouchak, A. (2013): Multivariate standardized drought index: a parametric multi-index model. - Advances in Water Resources 57: 12-18.

[12] Hao, Z., AghaKouchak, A. (2014): A nonparametric multivariate multi-index drought monitoring framework. - Journal of Hydrometeorology 15: 89-101.

[13] Hao, Z., Singh, V. P. (2015): Drought characterization from a multivariate perspective: a review. - Journal of Hydrology 527: 668-678.

[14] Hauser, M., Orth, R., Seneviratne, S. I. (2016): Role of soil moisture versus recent climate change for the 2010 heat wave in western Russia. - Geophysical Research Letters 43: 2819-2826.

[15] Hou, F. J., Chang, S. H., Nan, Z. B. (2009): Establish the pastoral agriculture system for desertification control in Minqin. - Pratacultural Science 26: 68-74.

[16] Kogan, F. N. (1995): Application of vegetation index and brightness temperature for drought detection. - Advances in Space Research 15: 91-100.

[17] Lei, T. J., Pang, Z. P., Wang, X. Y., Li, L., Fu, J., Kan, G. Y., Zhang, X. L., Ding, L. Q., Li, J. R., Huang, S. F., Shao, C. L. (2016): Drought and carbon cycling of grassland ecosystems under global change: a review. - Water 8: 460. 
[18] Li, Q., Zhang, Q., Huang, Q. Z., Shi, P. J. (2017): Nonparametric integrated agrometeorological drought monitoring in China: new monitoring technique and applicability. - Acta Geographica Sinica 73: 67-80.

[19] Li, W. G., Hou, M. T., Chen, H. L. (2012): Study on drought trend in south China based on standardized precipitation evapotranspiration index. - Journal of Natural Disasters 21: 84-90.

[20] Li, Z., Tan, D. (2013): The second modified perpendicular drought index (MPDI1): a combined drought monitoring method with soil moisture and vegetation index. - Journal of the Indian Society of Remote Sensing 41: 873-881.

[21] Liang, L., Zhao, S. H., Qin, Z. H., He, K. X., Chen, C., Luo, Y. X. (2014): Drought change trend using MODIS TVDI and its relationship with climate factors in China from 2001 to 2010. - Journal of Integrative Agriculture 13: 1501-1508.

[22] Liu, L. Y., Liao, J. S., Chen, X. Z., Zhou, G. Y., Su, Y. X., Xiang, Z. Y., Wang, Z., Liu, X. D., Li, Y. Y., Wu, J. P., Xiong, X., Shao, H. Y. (2017): The Microwave Temperature Vegetation Drought Index (MTVDI) based on AMSR-E, brightness temperatures for long-term drought assessment across China (2003-2010). - Remote Sensing of Environment 199: 302-320.

[23] Liu, X. F., Zhu, X. F., Pan, Y. Z., Li, S. S., Liu, Y. X. (2015): Agricultural drought monitor: progress, challenges and prospect. - Acta Geographica Sinica 70: 1835-1848.

[24] Lloyd-Hughes, B., Saunders, M. A. (2002): A drought climatology for Europe. International Journal of Climatology 22: 1571-1592.

[25] Maity, R., Suman, M., Verma, N. K. (2016): Drought prediction using a wavelet based approach to model the temporal consequences of different types of droughts. - Journal of Hydrology 539: 417-428.

[26] McKee, T. B., Doesken, N. J., Kleist, J. (1993): The relationship of drought frequency and duration to time scales. - Eighth Conference on Applied Climatology, Anaheim, California 17: 17-22.

[27] Mesquita, D. P. P., Gomes, J. P. P., Júnior, A. H. S., Nobre, J. S. (2017): Euclidean distance estimation in incomplete datasets. - Neurocomputing 248: 11-18.

[28] Palmer, W. C. (1965): Meteorological Drought, 30. - US Department of Commerce, Weather Bureau, Washington.

[29] Pang, S. F., Wei, W., Guo, Z. C,, Zhang, J., Xie, B. B. (2019): Agricultural drought characteristics and its influencing factors in Gansu Province based on TVDI. - Chinese Journal of Ecology 38(9): 1849-1860.

[30] Peng, J. F. (2011): Application of anti-drought measures in afforestation in arid desert area. - Gansu Forestry 1: 37-38.

[31] Price, J. C. (1985): On the analysis of thermal infrared imagery - the limited utility of apparent thermal inertia (for Heat Capacity Mapping Mission data of surface temperature). - Remote Sensing of Environment 18: 59-73.

[32] Price, J. C. (1990): Using spatial context in satellite data to infer regional scale evapotranspiration. - IEEE Transactions on Geoscience and Remote Sensing 28: 940-948.

[33] Ramkar, P., Yadav, S. M. (2018): Spatiotemporal drought assessment of a semi-arid part of middle Tapi River basin, India. - International Journal of Disaster Risk Reduction 28: 414-426.

[34] Ren, P. G., Zhang, B., Zhang, T. F., Li, X. Y., Chen, L., Lu, L. P. (2014): Trend analysis of meteorological drought change in Northwest China based on Standardized Precipitation Evapotranspiration Index. - Bulletin of Soil and Water Conservation 34: 182-187.

[35] Sandholt, I., Rasmussen, K., Andersen, J. (2002): A simple interpretation of the surface temperature/vegetation index space for assessment of surface moisture status. - Remote Sensing of Environment 79: 213-224.

[36] Santiago Beguería, Vicente-Serrano, S. M. (2013): Package 'SPEI'. http://digital.csic.es/handle/10261/10002. 
[37] Sheffield, J., Wood, E. F. (2012): Drought: past problems and future scenarios. International Journal of Digital Earth 5: 456-457.

[38] Shi, B. L., Zhu, X. Y., Hu, Y. C., Yang, Y. Y. (2017): Drought characteristics of Henan Province in 1961-2013 based on Standardized Precipitation Evapotranspiration Index. Journal of Geographical Sciences 27: 311-325.

[39] Shi, S. E., Wei, W., Yang, D., Hu, X., Zhou, J. J., Zhang, Q. (2018): Spatial and temporal evolution of eco-environmental quality in the oasis of SRB based on RSEDI. - Chinese Journal of Ecology 37: 1152-1163.

[40] Shi, S. Y. (2013): High-yielding cultivation techniques of red globe grapes in arid desert in Gansu Province. - Fruit Tree Technology and Information 5: 11-12.

[41] Shu, C. (2012): Study on problems and countermeasures of agricultural development in Dunhuang City. - Social Sciences Review 4: 59-60.

[42] Sun, H., Chen, Y. H., Sun, H. Q. (2012): Comparisons and classification system of typical remote sensing indexes for agricultural drought. - Transactions of the Chinese Society of Agricultural Engineering 28: 147-154.

[43] Tian, W. H., Chen, R. Y. (2011): Study on water saving agriculture model in northwest arid area. - Water Resources and Hydropower Technology of Gansu 47: 47-50.

[44] Van Rooy, M. (1965): A rainfall anomaly index independent of time and space. - Notos 14: 43-48.

[45] Vicente-Serrano, S. M., Beguería, S., López-Moreno, J. I. (2010): A multi-scalar drought index sensitive to global warming: the Standardized Precipitation Evapotranspiration Index. - Journal of Climate 23: 1696-1718.

[46] WMO (2012): Standardized Precipitation Index User Guide. - WMO-No. 1090, Geneva.

[47] Wu, L., Zhang, Y. Z., Xie, W. H., Li, Y., Yang, S. C. (2012): The inversion of soil water content by the improved apparent thermal inertia. - Remote Sensing for Land and Resources 25: 44-49.

[48] Xu, F. H., Cui, Y., Ma, C. B. (2004): Status quo of development of dryland water saving agriculture in Australia and its enlightenment. - World Agriculture 26: 27-29.

[49] Yang, X., Wu, J. J., Yan, F. (2009): Assessment of regional soil moisture status based on characteristics of surface temperature/vegetation index space. - Acta Ecologica Snica 29: 1205-1216.

[50] Yao, N., Li, Y., Lei, T. J., Peng, L. L. (2017): Drought evolution, severity and trends in mainland China over 1961-2013. - Science of the Total Environment 616-617: 73-89.

[51] Yu, M., Cheng, M. H. (2010): Drought monitoring Heilongjiang Province Based on NDVI-Ts Space. - Journal of Applied Meteorological Science 21: 221-228.

[52] Yu, M. X., Li, Q. F., Hayes, M. J., Svoboda, M. D., Heim, R. R. (2014): Are droughts becoming more frequent or severe in China based on the standardized precipitation evapotranspiration index: 1951 2010? - International Journal of Climatology 34: 545-558.

[53] Zargar, A., Sadiq, R., Naser, B., Khan, F. I. (2011): A review of drought indices. Environment Reviews 19: 333-349.

[54] Zawadzki, J., Kedzior, M. (2015): Soil moisture variability over Odra watershed: comparison between SMOS and GLDAS data. - International Journal of Applied Earth Observation and Geoinformation 51: 110.

[55] Zhang, Q., Zhang, L., Cui, X. C., Zeng, J. (2011): Progresses and challenges in drought assessment and monitoring. - Advances in Earth Science 26: 763-778.

[56] Zhang, Q., Yao, Y. B., Wang, Y., Wang, S. P., Jinsong Wang, J. S., Yang, J. H., Wang, J., Li, Y. P., Shang, J. L., Li, W. J. (2018): Characteristics of drought in Southern China under climatic warming, the risk, and countermeasures for prevention and control. Theoretical and Applied Climatology 136: 3-4.

[57] Zou, X. K., Ren, G. Y., Zhang, Q. (2010): Droughts variations in China based on a compound index of meteorological drought. - Climatic and Environmental Research 15: 371-378. 


\section{APPENDIX}

\section{Abbreviations}

AD: agricultural drought

ATI: Apparent Thermal Inertia

AVI: Anomaly Vegetation Index

CI: Compound Index

CSI: Critical Success Index

ED: Extreme Drought

EOD: Effect of Detection

EW: Extreme Wet

FAR: False Alarm Ratio

F-D-ND: Fluctuation type of Drought and Non-Drought

F-LD-MD-SD: Fluctuation type of LD, MD, SD

GLDAS: Global Land Data Assimilation System

IMAD: Integrated Meteorological and Agricultural Drought

LD: Light Drought

LST: Land Surface Temperature

LW: Light Wet

MADI: Meteorological and Agricultural Drought Index

MD: Moderate Drought

MeD: meteorological drought

MW: Moderate wet

$\mathrm{N}$ : Normal

Pa: percentage of Precipitation anomaly

PDSI: Palmer Drought Severity Index

POD: Probability of Detection

MMSDI: Modified Multivariate Standardized Drought Index

MODIS: Moderate Resolution Imaging Spector radiometer

MSDI: Multivariate Standardized Drought Index

NASA: National Aeronautics and Space Administration

NOAA: National Oceanic and Atmospheric Association

NPP: Net Primary Productivity

NDVI: Normalized Difference Vegetation Index

SD: Severe Drought

SED: Stable Extreme Drought

SLD: Stable Light Drought

SMD: Stable Moderate Drought

SND: Stable Non-Drought

SPEI: Standardized Precipitation Evapotranspiration Index

SPI: Standardized Precipitation Index

SSD: Stable Severe Drought

SSM: Standardized Soil Moisture Index

StD: Stable Drought

SW: Severe Wet

TVDI: Temperature Vegetation Dryness Index

VCI: Vegetation Condition Index

VSWI: Vegetation Supply Water Index 